\title{
A propósito do tratamento dos doentes epilépticos no Hospital Nacional dos Alienados durante os anos de 1912 e $1913^{*}$
}

\author{
Pelo Dr. Jefferson de Lemos \\ (Alienista da Assistência a Alienados) \\ Arquivos Brasileiros de Psiquiatria, Neurologia e Medicina Legal, Rio de Janeiro, n.1, 1915, p.5-30
}

\section{u U UUU}

O homem isolado da Humanidade é uma viciosa abstração.

Agir por afeição, e pensar para agir;

O homem torna-se cada vez mais religioso.

Augusto Comte

Entre os fenômenos da moléstia e os da saúde só existe diferença de intensidade.

Broussais

No organismo humano tudo é solidário, tudo concorre, tudo conspira, tudo consente.

Hipócrates

Tendo-nos sido confiada a direção do tratamento dos doentes denominados epilépticos, desde Maio de 1912, tentamos aplicar-lhes o método de tratamento que nos pareceu mais de acordo com a doutrina positivista, porém com a relatividade determinada pela anormal situação moral e social que resulta da hospitalização.

Apesar desse inconveniente que acarreta muitas dificuldades no tratamento, os resultados obtidos foram os mais animadores, pelo que expusemos no relatório anual, embora resumidamente, a maneira por que nos conduzíramos.

N.E. - Sobre este artigo, ver "O grande mal no Cemitério dos Vivos: diagnósticos de epilepsia no Hospital Nacional de Alienados", de Margarida de Souza Neves, neste número de História, Ciências, Saúde - Manguinhos.

N. da R. - A direção dos Arquivos Brasileiros de Psiquiatria, Neurologia e Medicina Legal por isso mesmo que ao fundálos também quis abrir um amplo campo de discussão para todas as doutrinas filosóficas, publica hoje os comentários do Dr. J. de Lemos ao seu relatório sobre o tratamento dos epilépticos que lhe foram confiados no correr dos anos de 1912 e 1913. Não tendo todos os nossos leitores uma noção exata do modo de pensar dos comtistas sobre umas tantas questões nos domínios da medicina, inserimos o presente artigo por julgá-lo ditado por um espírito sinceramente convicto das ideias de Augusto Comte. Julgando-o um documento psicológico de valor, recomendamo-lo à imparcialidade dos nossos leitores.

*Recebido em 5-XII-1914. 
Pensando mais tarde que a divulgação de tais resultados podia ter alguma utilidade prática, resolvemos publicá-los nos Arquivos de Psiquiatria, Neurologia e Medicina Legal, depois de devidamente autorizado, juntando então alguns desenvolvimentos tendentes a fundamentar o que disséramos, esclarecendo alguns pontos que naturalmente ali ficaram deficientes ou obscuros.

Só com muito atraso, porém, puderam ser escritos estes aditamentos, por motivos alheios à nossa vontade. Neles não faremos mais do que uma tentativa para expor resumidamente algumas vistas gerais sobre a parte da doutrina positivista que se refere à medicina e, particularmente, ao nosso especial assunto, a epilepsia.

Nesta última parte seguiremos de perto o Dr. Audiffrent, e no mais nos esforçaremos por ser tanto quanto pudermos, fiéis a Augusto Comte, segundo o exemplo dado pelos apóstolos sistemáticos do positivismo no Brasil, sob cuja direção nos sentimos felizes de ter recebido os principais esclarecimentos da admirável doutrina construída pelo incomparável Mestre.

A nossa própria insuficiência é que poderá explicar as lacunas e defeitos que aqui existirem.

\section{f $F$}

Antes de prosseguir, devemos, porém, prevenir de que não se irá encontrar nada de novo quanto aos meios de tratamento empregados, pois que os resultados ficam sempre dependendo mais da maneira de aplicá-los, ou do método seguido, do que da multiplicação desses meios; sendo necessariamente mais eficaz a prática que melhor tiver conseguido harmonizar-se com a verdadeira teoria científica da natureza humana.

É necessário também fazer notar que o problema médico ainda não havia recebido de Augusto Comte a última palavra quando a Humanidade passou pela irremediável catástrofe do seu prematuro desaparecimento objetivo. Muitas questões, principalmente as de ordem prática, ficaram esperando solução, e só o espírito geral da doutrina tem podido aí guiar seus discípulos.

Esta consideração só basta para mostrar a prudência que se deve ter ao tratar de tais assuntos. Também sentindo a necessidade de uma prática metódica para o tratamento dos doentes que nos foram confiados no Hospital Nacional, não tivemos nenhuma pretensão de dar o tipo da prática positiva, apenas nos havendo esforçado por nos aproximar dela.

\section{f $F$}

Não sabemos, por exemplo, ao certo, até que ponto o positivismo limitará o emprego das substâncias químicas ou farmacêuticas.

Não temos dúvida de que, num futuro mais ou menos remoto, quando a Humanidade tiver atingido ao seu estado normal de organização, estes meios só serão empregados excepcionalmente, pois que, além da ação eficaz da influência moral, então esclarecida da mulher, principalmente como mãe e esposa, assistida pelo sacerdócio positivista, ainda os sintomas graves da moléstia terão atingido a um grau mínimo.

Mas na época de anarquia que atravessamos, em que são tão comuns sintomas violentos, perturbando tão gravemente o equilíbrio orgânico, ameaçando-o muitas vezes de morte imediata, e quando as reações morais são tão prejudicadas pela falta de uma fé comum, não será lícita esta intervenção por estes meios que o esforço empírico da Humanidade tem já obtido, em muitos casos, de uma maneira tão admirável? 
Em uma carta ao Dr. Audiffrent, Augusto Comte referindo- se ao advento dos médicos positivistas dizia que eles em breve haviam de curar mais, drogando menos. ${ }^{1}$

Embora, pois, Augusto Comte na sua última moléstia se tivesse abstido de qualquer intervenção dessa natureza, parece-nos, pela carta acima aludida, que será sempre lícito, em certos casos, o emprego de alguns agentes químicos, cuja aplicação deverá ser sempre cercada da mais escrupulosa prudência. ${ }^{2}$

Era nos dois tratados de Moral, teórica e prática, que constituiriam o $2^{\circ}$ e $3^{\circ}$ volumes da Síntese subjetiva, que Augusto Comte ia abordar a solução final do problema médico.

As concepções positivas da existência, da saúde, da moléstia, sob a denominação comum de teoria vital, constituiriam o $4^{\circ}$ capítulo do volume correspondente a moral teórica, e seriam precedidas das teorias da unidade, do Grão-Ser (Humanidade), e do cérebro.

Mais de todos estes grandes assuntos só a teoria da moléstia não havia sido ainda apreciada sistematicamente, e se não fosse a referência antecipada que Augusto Comte lhe consagrou na sua correspondência com o Dr. Audifferent, teríamos ficado ainda com essa lamentável lacuna.

Esta correspondência, na parte a que nos referimos, consta de 8 cartas que foram, felizmente, suficientes para permitir os desenvolvimentos e aplicações da doutrina positiva, no que se refere ao organismo doente, realizadas por seus discípulos, principalmente o Dr. Audiffrent. ${ }^{3}$

Adiante transcrevemos os principais trechos dessa preciosa correspondência, e para que se tenha uma ideia de perda sofrida pela Humanidade com o prematuro desaparecimento do maior de seus Filhos, daremos também aqui os planos desses dois tratados, onde se evidenciará a importância e a magnitude dos assuntos que irão receber a última sanção do mais extraordinário dos Reformadores.

Eis o Relatório a que nos referimos. ${ }^{4}$

Cid. Dr. Diretor do Hospital Nacional de Alienados

PAVILHÃO GRIESINGER

(Seção de epilépticas - mulheres)

Aí vai relatado o que de essencial ocorreu nesta repartição hospitalar durante o ano de 1912. A diminuição sempre mantida do número dos ataques epilépticos, a partir de Junho, é o que desde logo se observa na estatística que a este acompanha. Este resultado foi conseguido principalmente com a modificação do regime alimentar que passou a ser vegetariano,

\footnotetext{
${ }^{1}$ V. Lettres d’Auguste Comte a divers. T. I. pág. 278.

${ }^{2}$ São indiscutíveis os perigos das intervenções por tais agentes, por isso que muitos deles são verdadeiros tóxicos, e porque nunca podemos medir suficientemente o grau e mesmo a natureza das reações de cada organismo; mas, dentro de certos limites, pesadas, tanto quanto possível, as circunstâncias particulares a cada caso, podemos sempre esperar conseguir reações que se aproximem das que foram observadas em circunstâncias mais ou menos idênticas. O maior ou menor acerto da medicação dependerá então da teoria que se tiver para explicar a natureza humana, ficando ainda tudo dependendo, é claro, da competência teórica e prática do médico.

${ }^{3}$ V. Dr. Audiffrent, Maladies du cerveau et de l'innervation (1874); Idem, Appel aux médecins (1862).

${ }^{4}$ As notas à margem que se encontram na presente publicação desse relatório não existiam no original, assim como também modificamos a sua redação em mais de uma passagem.
} 
descloruretado, excluindo-se ainda qualquer líquido excitante (café e congêneres). Foi esta a base do tratamento, estabelecida como único meio capaz de ser generalizado sem inconvenientes, salvo uma ou outra exceção que o critério médico poderia prevenir ou corrigir facilmente.

A prática, isto é, a ação do homem sobre o mundo ou sobre si mesmo, para ser racional, deve ser sempre dirigida pelo conhecimento das leis abstratas que lhe correspondam. Fora daí, caímos no puro empirismo. O empirismo é, no entanto, indispensável para completar o dogmatismo, porque só podemos conhecer um pequeno número de leis abstratas para um número infinito de casos concretos sobre que temos que agir. Mas esse pequeno número de leis abstratas, convenientemente aplicado, basta para dirigir nossa ação, instituindo uma suficiente previsão científica. ${ }^{5}$

$\mathrm{Na}$ prática médica temos de tomar em consideração o conjunto das leis naturais, e principalmente das que se aplicam diretamente ao homem: as biológicas, as sociológicas e as morais.

Mas quanto fica precária a ação moral sobre doentes segregados das famílias, vivendo em asilos, e a influência social em uma época de tão grande anarquia?

O recurso que ainda fica plenamente facultativo ao médico consiste nas intervenções que poderíamos chamar biológicas, isto é, as que visam modificar os fenômenos vitais, agindo sobre a parte física (corpórea) do nosso organismo. Modificadas favoravelmente as vidas vegetativa e animal, reações cerebrais benéficas são sempre possíveis, e assim atuamos também, mas indiretamente, sobre o estado cerebral (moral) dos doentes.

De todos os meios capazes de modificar a vida vegetativa, impõe-se à evidência a influência do regime alimentar como o mais importante. Também a única lei abstrata conhecida, capaz de guiar a terapêutica física é justamente a que regula a alimentação, mostrando-nos que "todas as substâncias assimiláveis são excitantes ou calmantes, conforme são ingeridas em dose acima ou abaixo daquela em que se constituem normalmente alimentos". ${ }^{6}$

Nestas condições, depois de instituir um regime sem excitantes, quanto à qualidade da alimentação, como meio geral de tratamento, o que era sobremodo requerido tratando-se de epilépticos, por serem doentes cujo cérebro é sede, periódica ou continuamente, de uma excitação mais ou menos violenta, era mister completar o regime alimentar geral fazendo variar a dose do alimento conforme o estado particular de cada doente. Assim o fizemos.

Quando estes meios não bastavam, intervínhamos com os revulsivos, derivativos e depleções sanguíneas, tendo sido estas últimas, aliás, raramente necessárias.

O emprego das sangrias, tão desprezado hoje, tem seu fundamento na existência de inflamações que quase sempre acabam por estabelecer-se nos órgãos e tecidos, depois de demasiado estímulo das respectivas funções, quaisquer que tenham sido as origens da excitação funcional.

\footnotetext{
${ }^{5}$ A verdadeira diferença entre a teoria e a prática consiste na generalidade e simplicidade de uma, a teoria, e na particularidade e complicação de outra, a prática. Pela teoria, abstraímos do corpo para considerar os fenômenos e instituir as leis desses fenômenos, abstratos, portanto. Na prática temos que agir, modificando os fenômenos de cada corpo, de acordo com as leis instituídas pela teoria; mas não podemos mais abstrair dos outros fenômenos que concorrem em cada caso. Daí a sua complicação e a necessidade do em empirismo para completar o dogmatismo, por nos ser impossível descobrir as leis concretas. A ciência só pode ser abstrata. (V. Teixeira Mendes, As últimas concepções de Augusto Comte, Sétima conferência (Conjunto do dogma).

${ }^{6}$ Esta lei foi descoberta por Augusto Comte.
} 
Seja por adquirir a inflamação uma intensidade excepcional, que pode determinar como consequência a destruição dos tecidos atingidos, seja por sua demasiada duração, entretendo ou determinando por si só o estado mórbido, mesmo quando os outros motivos da moléstia tenham desaparecido, o deflúvio sanguíneo torna-se sempre, nestes casos, um recurso sem equivalente na arte médica.

Procuramos sempre reduzir o mais possível o emprego dos agentes químicos (aliás, muitas vezes úteis), por serem os mais empíricos (sua maneira de atuar sobre o organismo nos é quase inteiramente desconhecida).

E de fato. A complicação superior dos fenômenos vitais impedirá sempre numa qualquer apreciação da química chamada biológica.

A vida sendo "o resultado do duplo movimento contínuo e geral de composição e decomposição que se estabelece entre o indivíduo e o meio que o cerca" ${ }^{7}$, impossível se torna fazermos uma apreciação, mesmo aproximada, destas íntimas combinações, pois que essa harmonia entre a composição e a decomposição cessa com a própria vida. Desde que o animal morre, o movimento de decomposição só subsiste. Quando, pois, os elementos componentes dos nossos tecidos ou dos nossos humores são analisados em sua composição química, já não são mais o que eram quando faziam parte do organismo vivo, apresentando-se, ao contrário, muito diferentes do que eram no estado vital. A própria estrutura é também afetada nesta insuperável emergência.

A análise das íntimas combinações orgânicas sendo impossível, a síntese que deveria então reconduzir ao estado vital, fica também impossível. E deve-se notar que a chamada química orgânica é uma química de substâncias tão mortas como as substâncias minerais; a única diferença consiste que aquelas se originam das decomposições orgânicas determinadas pelo movimento vital. $^{8}$

Estas considerações são ainda de molde a fazer reconhecer a necessidade de nos libertarmos das aspirações absolutas sobre a terapêutica química, assim como também para nos desiludir sobre as vantagens do método experimental aplicado à biologia. ${ }^{9}$

Quanto à terapêutica, basta considerar que é impossível qualquer previsão sem o conhecimento abstrato dos fenômenos que pretendemos modificar; e como dissemos, os fenômenos íntimos das composições e decomposições orgânicas escapam à nossa apreciação química.

Essas intervenções são, pois, muito empíricas, salvo quando podem entrar na lei geral acima indicada, por serem assimiláveis, lei essa, que é, no entanto, biológica. Nos outros casos, temos sempre que contar com as reações particulares a cada organismo, variáveis de um individuo para outro, e até no mesmo individuo, conforme as circunstâncias de cada momento.

\footnotetext{
${ }^{7}$ Esta definição de vida é devida a Blainville que Augusto Comte designou como o último (na série histórica) dos grandes biologistas.

${ }^{8}$ Assim se reconhece que as pretensas químicas denominadas biológica e orgânica não representam mais do que simples confusões entre estudos propriamente biológicos ou propriamente químicos. Se o estado vital se liga intimamente aos fenômenos químicos, os fenômenos da vida não ficam, por isso, constituindo menos uma categoria de fenômenos à parte, com suas leis próprias. O estudo dos fenômenos vitais ou biologia constitui, pois, uma ciência deferente da química que estuda a composição dos corpos. Não há lugar para uma química biológica e uma química orgânica destituídas da química inorgânica ou mineral, cujas leis são as mesmas.

${ }^{9} \mathrm{O}$ mesmo podemos dizer da análise anatômica microscópica, porque, na maioria das vezes, impossível é dizer se uma alteração coexistiu com a vida, ou se é um resultado da decomposição cadavérica.
} 
É incontestável que certas substâncias têm efeitos mais constantes que outras. Isto que pode ser devido à natureza delas, pode também ser conseguido, até certo ponto, fazendo variar a sua dosagem. Mas mesmo quando essa ação parece mais constante, uma observação mais cuidadosa fará reconhecer as diferenças de cada caso. ${ }^{10}$

Foi a constatação dessa constância de ação que parecem ter algumas substâncias sobre o nosso organismo que conduziu à noção absoluta, e portanto, errônea, sobre a especificidade. ${ }^{11}$

Não é aqui lugar de tentar fazer uma análise desta questão, mas o que dissemos julgamos suficiente para justificar nossas reservas quanto à medicação tida como específica.

Consideremos ainda que os fenômenos vitais não apresentam só esta instabilidade geral que lhes é peculiar, e sim também extrema variabilidade, conforme as circunstâncias especiais a cada caso, pois se modificam eles sob as múltiplas condições de sexo, idade, clima, gênero de alimentação; e no mesmo individuo, conforme os diferentes estados tão variáveis do cérebro e do corpo, na saúde como na moléstia. Para que pudéssemos, pois, fazer previsões científicas quanto à influencia dos agentes químicos no nosso organismo, precisava que conhecêssemos, por um lado, a natureza íntima das trocas orgânicas nos estados de saúde, e por outro lado, as suas perturbações nos estados de moléstia, mas tomando ainda em consideração todas as variações dependentes das condições especiais a cada caso que se considera.

A insolubilidade do problema, quimicamente considerado, é evidente. Temos que nos valer do empirismo, mesmo talvez quanto à intervenção nas funções químicas mais elementares do organismo, a elaboração dos alimentos, que constitui o primeiro grau de sua vivificação. Assim chegamos a compreender todo o alcance e rigor da sentença que Augusto Comte proferiu no leito de morte: "a medicina peca por um vício lógico capital, pois está sempre reduzida a agir por meios gerais em casos particulares".

Estas considerações mostram porque e procuramos sempre agir de preferência pelos meios que primeiro apontamos e que constituem o que Broussais ${ }^{12}$ denominava medicina fisiológica, $\mathrm{e}$ porque não fizemos uso sistemático dos meios químicos, deixando-os para quando os outros não tivessem sido suficientes. Por este modo ainda logramos evitar o hábito do organismo, conseguindo assim o máximo de efeito deles, no momento oportuno, sem ser necessário recorrer a grandes dosagens. Mas nunca nos iludimos quanto à natureza precária destes meios, e sempre convencido de que, na Humanidade regenerada, cada vez o emprego deles será mais reduzido, por desnecessários.

E com efeito. De todos os meios capazes de estabelecer equilíbrio do nosso organismo, o mais eficaz, quando pode ser convenientemente aplicado, consiste em promover uma reação orgânica geral pela excitação normal do aparelho cerebral. Mais de acordo com a unidade total de nossa

\footnotetext{
${ }^{10}$ Basta considerar que a ação sobre o organismo nunca se faz exclusivamente sobre um só tecido, sistema ou parênquima, ou mesmo sobre algum órgão ou aparelho, e sim sobre a totalidade deles, variando apenas o grau e a natureza reação de cada um, e devendo-se ainda de tomar em consideração as reações mútuas despertadas entre eles. Assim se compreende bem a dificuldade que há em apreciar, na prática, a conveniência ou não dessas intervenções em cada organismo que se pretende modificar favoravelmente.

${ }^{11}$ É conveniente notar que hoje a noção de especialidade se materializou ainda mais, com a teoria microbiana, considerando-se específico o medicamento que se imagina capaz de destruir, no nosso organismo, uma espécie determinada de micróbio.

${ }^{12}$ Segundo a apreciação de Augusto Comte, Broussais foi o espírito mais genial de que a medicina se possa honrar, depois de Hipócrates.
} 
natureza, e com a presidência que no consenso orgânico cabe ao cérebro, é por uma reação moral conveniente que podemos obter um resultado mais completo, e um modo mais racional $\mathrm{e}$ mais sistemático sem ser nunca perturbador. Mas só quando a Humanidade estiver regenerada pode ele ser aplicado em toda a sua plenitude. Só então, o equilíbrio social ligado à regeneração individual, permitirá a um sacerdócio, geralmente respeitado exercer o ofício normal de médico (que será sempre gratuito), combinando todos os resultados da ciência com a sua influência moral, semelhante à que teve o sacerdócio católico durante a Idade Média. E a sua ação será ainda facilitada porque a regeneração dos costumes terá feito desaparecer o maior número das moléstias que afligem o nosso desmoralizado presente.

Fica assim exposto o método de tratamento que procuramos seguir em todos os casos, dando as razões de sua preferência; mas só o aplicamos quanto nos foi possível com a deficiência que não pode ser evitada no regime hospitalar. Contudo, os resultados não desmentiram nossa expectativa, e para isso concorreu o contínuo zelo da enfermeira a quem, em boa hora, foram confiados os doentes deste pavilhão.

Para termos a confirmação de que as modificações das manifestações epilépticas obtidas dependeram do método de tratamento seguido, recorremos às estatísticas dos anos anteriores, a fim de verificar se teria já havido, alguma vez, um período tão longo de melhoria dos doentes.

Desde 1907, até onde remontam as estatísticas que encontramos, só em 4 meses o número de ataques das 24 doentes que existem nesse pavilhão (dado que a lotação tivesse sido sempre preenchida), foi inferior a 100: (95 e 99 em Janeiro e Fevereiro de 1907; 88 e 90 em Dezembro de 1909 e Janeiro de 1910). Nos outros meses esse número oscilou entre 108 e 336, ficando 40 vezes abaixo de 200, 15 vezes abaixo de 300 e 5 vezes acima desse último número.

No entanto, tendo instituído a mudança do regime em 15 de Maio, mês em que passamos a servir no Hospício, nunca mais o número dos ataques foi além de 94, a partir do mês seguinte, como se verifica do quadro junto, e tudo nos leva a esperar este ano um melhor resultado, tendo já atingido um mínimo de 54 .

Mas não é tudo. Pudemos ainda notar a atenuação da violência dos ataques e a melhoria geral do estado físico e moral das doentes, de modo que, ao lado de um maior equilíbrio vegetativo ainda houve diminuição dos acessos de agitação tão comuns nos epilépticos.

Sem entrar em detalhes quanto ao que notamos particularmente sobre algumas doentes que prenderam mais a nossa atenção, aí ficam, geralmente assinalados o que fizemos e observamos. ${ }^{13}$

Oxalá pudéssemos estender a todos os doentes existentes no Hospital Nacional o mesmo método de tratamento.

\section{f $F$}

\footnotetext{
${ }^{13}$ A presente publicação nos oferece ocasião de relatar, oportunamente, essas observações mais particulares.
} 
A propósito do tratamento dos doentes epilépticos no Hospital Nacional dos Alienados durante os anos de 1912 e 1913

\section{PAVILHÃO GUISLAIN}

(Seção dos epilépticos - homens)

Ainda nesta seção foi empregado o mesmo método de tratamento; mas infelizmente os resultados não foram tão felizes como os obtidos no pavilhão de Griesinger. ${ }^{14}$

Diversos motivos terão concorrido para isso. Entre eles devemos constatar a disciplina mais difícil de ser mantida entre homens, dificultando, por sua vez, a vigilância dos guardas e enfermeiros. Como consequência, o regime seria muitas vezes burlado, o que efetivamente sucedeu. Chegamos assim a reconhecer a necessidade de um maior número de guardas para tais doentes.

Além dessa, uma outra consideração tem aqui todo o cabimento. A superioridade do organismo feminino sobre o masculino terá em grande parte concorrido para a diferença do resultado, em virtude das reações mais prontas e mais eficazes que em geral apresenta o primeiro em relação ao segundo, o que resulta das ligações mais íntimas que aquele mantém entre o físico e o moral.

Contudo, não devem os esquecer que a epilepsia é uma afecção mais própria do homem, por atingir os órgãos da atividade, e quem comparar o comum dos doentes epilépticos dos dois sexos há de verificar que o cérebro masculino é geralmente mais afetado nestes casos do que os femininos, no seu conjunto, tendendo aquele com mais facilidade para a idiotia, o que talvez possa ainda ser invocado como uma prova da superioridade da organização feminina.

Juntamos também aqui a estatística do movimento geral da Seção e o quadro representativo do número de ataques. Por este vereis que os acessos convulsivos parecem ter aumentado de Agosto em diante. Mas foi isso devido a doentes gravemente afetados que vieram de outras seções e só um deles deu um contingente de 88 ataques no mês de Outubro. Se compulsardes, porém, as estatísticas anteriores, reconhecereis que, apesar dessas aparências, ainda há vantagem deste ano sobre os anteriores, em que muitas vezes a cota mensal excedeu a 400 e mesmo 500. Assim, tomando englobadamente os 2 anos anteriores verifica-se que o número total anual foi respectivamente de 3200 e 4575, para 2381 em 1912.

Ao terminar este relatório desejávamos formular um voto. É para que sejam instituídas, em breve tempo, colônias próprias para epilépticos, de ambos os sexos, como já tendes mais de uma vez reclamado.

Além de melhorar as condições gerais de existência desses doentes, poderiam ainda proporcionar-lhes as vantagens de toda a sorte que advém do emprego de sua atividade em trabalhos que lhes fossem apropriados. E tanto mais que uma conveniente organização dessas colônias não exigiria grandes despesas, pelas razões já bem conhecidas.

\section{f $F$}

Como se evidencia pelo que aí ficou dito, o método que seguimos apresenta grande simplicidade nos meios terapêuticos físicos (que visam a parte corpórea do organismo) e isso só basta para estabelecer um contraste com as práticas médicas hoje correntes.

Mas não constitui essa a principal diferença entre a medicina atual e a que terá de prevalecer no estado normal da Humanidade. A medicina positiva, baseada no verdadeiro conhecimento

\footnotetext{
${ }^{14}$ A publicação tardia destas notas oferece-nos ocasião ainda de constatar, como será relatado mais adiante, os melhores coeficientes obtidos em 1913 e 1914.
} 
da natureza humana, será sempre mais moral do que física. Suas intervenções quanto aos sintomas vegetativos ou animais, visarão apenas modificar aqueles que por sua natureza ou intensidade se tornarem por demais perturbadoras. E procurará sempre respeitar as reações mútuas entre o cérebro e o corpo, no que consiste mesmo, talvez, a principal dificuldade da arte médica.

Para chegar-se a esse resultado é necessário, porém, o conhecimento completo de nossas condições de existência corporais e cerebrais, o que equivale a admitir a necessidade de conhecer todas as leis estáticas e dinâmicas a que se acha subordinado o organismo humano tanto físico como moral. Só assim é que podemos nos dar conta de todas as influências que atuam sobre o nosso organismo, seja determinando o estado chamado de saúde, seja determinando as perturbações desta, ou o estado de moléstia. Também só então podemos reconhecer toda a extensão e a verdadeira natureza do problema médico.

Sem pretender, de nenhum modo, desenvolver considerações tão difíceis, vamos, no entanto, indicar o que julgarmos suficiente à aceitação dessas afirmações.

Todo ser vivo supõe um certo número de ações e reações entre ele e o meio físico que o cerca.

Este meio que deve ser sempre constituído por uma mistura de ar e água (ar dissolvido n’água ou água dissolvida no ar $)^{15}$, constitui para todo ser o alimento, o estimulante, e o regulador dos fenômenos vitais.

O homem, sendo o animal mais evoluído, é também aquele em quem esses fenômenos convergem na maior intensidade, o que justifica a designação de microcosmo que lhe davam os antigos.

Mas a existência social à qual o homem se acha ainda subordinado, impõe mais, para a sua completa apreciação, o conhecimento da influência sobre ele exercida pela ação contínua da Humanidade. Constituída pelo conjunto dos seres convergentes, passados, futuros e presentes, este verdadeiro Grande-Ser que nos domina atua sobre o homem por intermédio do cérebro. Por outro lado, só podemos conceber a ação recíproca entre o homem e o mundo como modificada ainda pela ação da Humanidade, segundo o aforismo entre o homem e o mundo é preciso a Humanidade.

O organismo humano estando assim subordinado a tantas e tão variadas influências, cósmicas e sociais, compreende-se que para a concepção científica (positiva) de sua existência normal, que constitui o estado de saúde, como para a concepção positiva da moléstia, que é o resultado de uma alteração qualquer daquele estado, temos que tomar em consideração todas aquelas condições, além das que resultam da própria constituição individual, física e cerebral.

Assim se evidencia que o problema médico, indissoluvelmente ligado ao problema humano total, é como este, extremamente complexo, e sua apreciação tem de ser sintética, isto é, tem de abraçar o conjunto do saber da Humanidade. Esta condição impõe aos médicos a necessidade de uma cultura teórica enciclopédica, assim como a indivisibilidade de sua arte.

Mas é indispensável ainda reconhecer que os conhecimentos humanos ficam postos entre dois limites intransponíveis: a exiguidade do nosso planeta no concerto astronômico universal, e a fraqueza intrínseca do poder mental da Humanidade, cujas tradições mesmas só são conhecidas desde um período relativamente recente.

\footnotetext{
${ }^{15}$ Apanhado devido ao biologista Blainville.
} 
Esta irremediável deficiência dos dados bastaria por si só para impor fatalmente um limite às nossas concepções reais, se não nos fosse ainda interdito penetrar a natureza mesma dos fenômenos que nos são mais familiares.

Não podendo ter conhecimentos absolutos sobre coisa nenhuma, ficamos sempre reduzidos a "fazer a hipótese mais simples e mais simpática, de acordo com o conjunto dos dados adquiridos". Tal é a 1르 lei de Filosofia Primeira que é, antes de tudo, uma lei lógica, e cujo cabal preenchimento indica o estado normal do raciocínio ou o estado chamado de razão.

Reconhecendo a impossibilidade de investigar as causas primárias e finais, a maturidade de nossa razão contenta-se em descobrir as leis dos fenômenos que nos afetam, de modo a sistematizar tudo o que for necessário ao conjunto de nossas necessidades físicas, intelectuais e sobretudo morais. A sintese, que representa o conjunto das concepções próprias ao estado normal da Humanidade, não pode assim deixar de ser subjetiva. A análise teórica, para não ser viciosa, só deve ser feita tanto quanto baste à construção dessa síntese. Uma vez conhecida a síntese, a análise deve ficar-lhe sempre subordinada, a fim de serem evitadas perigosas aberrações.

A aceitação do problema humano, com a complexidade que ele naturalmente tem, exige, portanto, tendências sintéticas do espírito, e disposições simpáticas do coração. A síntese supõe, antes de tudo, a simpatia.

Sem humildade e sem veneração, como limitar no homem as pretensões a tudo conhecer e a tudo dominar? Sem um suficiente surto de altruísmo, principalmente da bondade, como conduzir nossa inteligência para as preocupações sociais e morais que constituíram sempre o verdadeiro objetivo de todos os esforços teóricos e práticos realizados pela Humanidade?

Mas a dificuldade de preencher hoje estas duas condições do espírito e do coração explica por que as classes teóricas ainda se conservam, em sua quase totalidade, alheias ao movimento moderno de reorganização social. A preocupação demasiada dos detalhes, resultante de uma preparação teórica incompleta, desenvolvendo o espírito de análise, além do que era exigido pela sistematização final dos conhecimentos humanos, tem impedido cada vez mais os cientistas de conceber as verdadeiras condições do problema humano.

Por outro lado, o espírito de análise contrariando as concepções gerais, perturba ainda o surto de nossos melhores afetos, de acordo com a observação de A. Comte que liga os pensamentos gerais aos sentimentos generosos.

Voltando, porém, ao nosso objetivo, notemos que a existência humana ficando subordinada a tantas condições, individuais (morais), coletivas (sociais), e materiais (físicas), para que possa haver uma harmonia total entre elas, necessário se torna que se achem todas suficientemente ligadas sem nenhum conflito essencial.

É preciso que o homem sinta que dentro de si tudo é unido e harmônico, e ao mesmo tempo reconheça sua dependência para com tudo que o cerca: materialmente, para com o mundo e espiritual e moralmente, para com a Humanidade. ${ }^{16}$ Esta harmonia cerebral que exige ainda um suficiente equilíbrio vegetativo e animal é o que constitui a unidade, que para conciliar-se com o predomínio, cada vez maior da Humanidade tem de ser altruísta, isto é, tem de ser realizada mediante o ascendente contínuo do amor na nossa organização cerebral.

${ }^{16}$ A dependência material foi reconhecida, durante o estado fetíchico que muito se relaciona com a noção dessa dependência. O conhecimento da nossa dependência para com a Humanidade liga-se ao estado positivo final. 
Mas o predomínio da Humanidade só pode ser obtido por intermédio da inteligência, porque é através dela que podemos nos colocar em relação com o meio exterior. A inteligência é que nos leva a reconhecer, fora de nós, o ser que nos domina, a Humanidade. ${ }^{17}$

Mas para que o equilíbrio social e moral seja completo, é necessário que os vivos reconheçam sua dependência para com os mortos e os não natos, e que o homem sinta fundamentalmente o mesmo, através de todas as idades de sua existência individual. É preciso, em suma, que a unidade seja completada pela continuidade. Tal é o estado religioso, termo final de todos os aperfeiçoamentos humanos, segundo a lei moral "o homem torna-se cada vez mais religioso".

Foi o que Augusto Comte tornou possível aos que, libertos da teologia e da metafísica, tiverem o coração bem formado, construindo este estupendo monumento da sabedoria humana que é a Religião da Humanidade.

No entanto, só a palavra religião faz com que os revolucionários e os céticos condenem a priori o Positivismo, seja por se ligar comumente a este vocábulo uma acepção mística, sobrenatural, seja porque ele lembra sempre a disciplina moral que procuram evitar aqueles que se acostumaram a erigir a razão individual, a que chamam consciência, como juiz supremo de toda sua conduta.

A seguinte passagem do Catecismo positivista faz, porém, dissipar qualquer dúvida que se possa ter quanto à interpretação positiva do termo religião, assim como demonstra que a arte médica deve ficar incorporada ao sacerdócio: ${ }^{18}$

"O Sacerdote. Este nome (religião), minha querida filha, não apresenta, de fato, pela sua etimologia, nenhuma solidariedade necessária com as opiniões quaisquer que possam ser empregadas para atingir o fim que ele designa. Em si mesmo, este vocábulo indica o estado de completa unidade, que distingue nossa existência, a um tempo pessoal e social, quando todas as suas partes, tanto morais como físicas, convergem habitualmente para um destino comum. Assim, esse termo seria equivalente à palavra síntese, se esta não estivesse, não por sua própria estrutura, mas segundo um uso quase universal, limitada ao só domínio do espírito, ao passo que a outra compreende o conjunto dos atributos humanos. A religião consiste, pois, em regular cada natureza individual e congregar todas as individualidades; o que constitui apenas dois casos distintos de um problema único. Porquanto todo homem difere sucessivamente de si mesmo tanto quanto difere simultaneamente dos outros, de maneira que a fixidez e a comunidade seguem leis idênticas.

Não podendo semelhante harmonia, individual ou coletiva, realizar-se nunca plenamente em uma existência tão complicada como a nossa, esta definição da religião caracteriza, portanto, o tipo imutável para o qual tende cada vez mais o conjunto dos esforços humanos. Nossa felicidade e nosso mérito consistem sobretudo em nos aproximarmos tanto quanto possível dessa unidade, cujo surto gradual constitui a melhor medida do verdadeiro aperfeiçoamento. Quanto mais se desenvolvem os diversos atributos humanos, tanto mais importância adquire o concurso habitual deles; este, porém, se tornaria talvez mais difícil se essa evolução não tendesse espontaneamente a tornar-nos mais disciplináveis, como breve vo-lo explicarei.

\footnotetext{
${ }^{17}$ A harmonia entre os indivíduos, entre as famílias e entre as pátrias, só pode ser conseguida, portanto, pela disciplina da inteligência, mediante uma doutrina demonstrável, única que pode ser universalmente aceita, tendo por órgão um sacerdócio moralizado.

${ }^{18}$ V. Catecismo Positivista, edição Brasileira, trad. por M. Lemos, págs. 42 a 49.
} 
A propósito do tratamento dos doentes epilépticos no Hospital Nacional dos Alienados durante os anos de 1912 e 1913

O apreço que sempre se ligou a esse estado sintético devia concentrar a atenção sobre o modo de o instituir. Foi-se assim levado, tomando o meio pelo fim, a transferir o nome de religião ao sistema qualquer das opiniões correspondentes. Porém, por mais inconciliáveis que pareçam, à primeira vista, essas numerosas crenças, o positivismo as combina essencialmente, referindo cada uma ao seu destino temporário e local. Não existe, no fundo, senão uma única religião, ao mesmo tempo universal e definitiva, para a qual tenderam cada vez mais as sínteses parciais e provisórias, tanto quanto o comportavam as respectivas situações. A esses diversos esforços empíricos sucede agora o desenvolvimento sistemático da unidade humana, cuja constituição direta e completa tornou-se possível graças ao conjunto de nossas preparações espontâneas. É assim que o positivismo dissipa naturalmente o antagonismo mútuo das diferentes religiões anteriores, formando seu domínio próprio do fundo comum a que todas se reportaram de modo instintivo. A sua doutrina não poderia tornar-se universal, se, apesar de seus princípios antiteológicos, o seu espírito relativo não lhe ministrasse necessariamente afinidades essenciais com cada crença capaz de dirigir passageiramente uma porção qualquer da Humanidade.

A Mulher. Vossa definição da religião me satisfará de todo, meu pai, se vos for possível esclarecer suficientemente a grave dificuldade que me parece resultar de sua excessiva extensão. Porquanto, caracterizando nossa unidade, vós incluis nela tanto o físico como o moral. Com efeito, eles estão de tal maneira unidos que uma perfeita harmonia não pode nunca estabelecerse quando se quer separá-los. Contudo, não poderia habituar-me a fazer entrar a saúde na religião, de modo a prolongar até a medicina o verdadeiro domínio da moral.

O Sacerdote. Entretanto, minha filha, o cisma arbitrário que desejais manter, seria diretamente contrario à nossa unidade. Tal divórcio só é realmente devido à insuficiência da última religião provisória, que não pôde disciplinar a alma senão abandonado aos profanos o domínio do corpo. Nas antigas teocracias, que constituíram o modo mais completo e mais duradouro do regime sobrenatural, esta vã divisão não existia; a arte higiênica e médica foi sempre aí um simples anexo do sacerdócio.

Tal é, com efeito, a ordem natural, que o positivismo vem restabelecer, consolidar, em virtude de sua plenitude característica. A arte humana e a ciência humana são respectivamente indivisíveis como os diversos aspectos peculiares ao destino comum de ambas (o homem) no qual tudo se acha constantemente ligado. Não se pode mais tratar bem nem do corpo nem da alma, por isso mesmo que o médico e o padre estudam exclusivamente o físico ou o moral; sem falar do filósofo que, durante a anarquia moderna, arrebata ao sacerdócio o domínio do espírito, deixando-lhe o do coração.

As moléstias cerebrais, e mesmo muitas outras, aí estão mostrando todos os dias a impotência de toda medicação restrita aos órgãos mais grosseiros. Não é menos fácil reconhecer a insuficiência de todo sacerdócio que quiser dirigir a alma desprezando sua subordinação ao corpo. Esta separação duas vezes anárquica deve, pois, cessar irrevogavelmente, mediante uma sábia reintegração da medicina no domínio sacerdotal, quando o clero positivo houver preenchido suficientemente suas condições enciclopédicas. O ponto de vista moral é, com efeito, o único próprio para fazer prevalecer prescrições higiênicas, tanto privadas como públicas. Isto verificase facilmente pelos vãos esforços dos médicos ocidentais para regularem nossa alimentação habitual, desde que ela não é mais dirigida pelos antigos preceitos religiosos. Nenhuma prática incômoda pode ser ordinariamente aceita em nome só da saúde pessoal, que deixa cada um juiz 
de si mesmo: porquanto amiúde os inconvenientes atuais e certos nos abalam mais do que as vantagens remotas e duvidosas. É necessário invocar uma autoridade superior a toda individualidade, para impor, mesmo nos casos mínimos, regras verdadeiramente eficazes, fundadas então sobre uma apreciação social que jamais comporta indecisões.

A Mulher. Depois de ter assim reconhecido, em toda a sua plenitude, o domínio natural da religião, eu quisera saber, meu pai, em que consistem as condições gerais dela. Frequentes vezes ma tem representado como dependendo unicamente do coração. Sempre pensei, porém, que o espírito aí também concorre. Poderei compreender claramente as suas atribuições respectivas?

O Sacerdote. Esta apreciação resulta, minha filha, de um exame aprofundado da palavra "religião", talvez o mais bem composto de todos os termos humanos. Ele é construído de maneira a caracterizar uma dupla ligação, cuja noção exata basta para resumir toda a teoria abstrata de nossa unidade. Com efeito, a fim de constituir uma harmonia completa e duradoura, é preciso ligar o interior pelo amor, e o religar ao exterior pela fé. Tais são, em geral, as participações necessárias do coração e do espírito nesse estado sintético, individual ou coletivo.

A unidade supõe, antes de tudo, um sentimento ao qual se possam subordinar os nossos vários pendores. Porquanto as nossas ações, e os nossos pensamentos sendo sempre dirigidos pelos nossos afetos, a harmonia humana ficaria impossível se estes não fossem coordenados sob um instinto preponderante.

Mas esta condição interior da unidade não bastaria se a inteligência não nos fizesse reconhecer, fora de nós, uma potência superior ${ }^{19}$, a que a nossa existência deve sempre submeter-se, mesmo quando a modifica. É a fim de melhor sofrermos esse império supremo que a nossa harmonia moral, individual, ou coletiva, se torna sobretudo indispensável. Reciprocamente, esta preponderância do exterior tende a regular o interior, favorecendo o ascendente do instinto mais conciliável com semelhante necessidade.

Assim, as duas condições gerais da religião são naturalmente conexas, sobretudo quando a ordem exterior pode tornar-se o objeto do sentimento interior."

Como dissemos, a leitura deste trecho de Augusto Comte basta para dissipar nas almas sinceras qualquer preconceito que possam ter contra o Positivismo, por ele se apresentar como verdadeiramente é, uma religião, e mostra que a medicina, incorporada à moral, será reintegrada nas funções sacerdotais, das quais só se separou enquanto durou a instituição analítica das ciências inferiores que deviam servir de base à sociologia e à moral cientificas.

Foi na civilização grega que esta construção analítica teve início com Tales, e prolongou-se até nossos dias, quando a fundação da biologia por Bichat permitiu que se retomasse a solução do problema humano de maneira sintética, e com a plenitude com que havia sido posto pela teocracia.

A importância do conhecimento desse movimento humano, a fim de compreender-se a verdadeira natureza do problema moderno, obriga-nos a fazer-lhe uma referência, embora resumida. Pode-se sintetizar esse movimento, que constitui a evolução ocidental, dizendo que ele consistiu em fazer a Humanidade passar da teocracia para a sociocracia. ${ }^{20}$

\footnotetext{
${ }^{19}$ Esta potência superior é o conjunto da ordem natural - J. L.

${ }^{20}$ A sociedade moderna acha-se ainda na transição de um estado para outro.
} 
A propósito do tratamento dos doentes epilépticos no Hospital Nacional dos Alienados durante os anos de 1912 e 1913

O estado teocrático, ou politeísmo conservador, é qualificado por Augusto Comte como o mais completo dos regimes que preparam o estado normal da Humanidade, a sociocracia. A moral, teórica e prática, era considerada como a ciência por excelência, segundo o preceito peculiar à teocracia: conhece-te a fim de melhorar-te. A inteligência era sempre votada ao seu verdadeiro destino, o serviço contínuo da sociabilidade; e a indivisibilidade teórica reconhecida pelo seu sacerdócio, cujos membros eram ao mesmo tempo legisladores, juízes, médicos, astrônomos, filósofos, poetas e pontífices.

Mas essa admirável tentativa da sabedoria humana teve de abortar, por prematura. A resolução final do problema humano que resultava da instalação da sociocracia, mediante uma completa combinação entre a ordem e o progresso, necessitava da fundação da sociologia e da moral científicas. Mas a fundação destas duas ciências ficava dependendo do conhecimento das ciências preliminares, cuja elaboração era muito difícil, e tinha de ser demorada, porque a Humanidade não dispõe, a cada momento, de um Aristóteles, ou de um Arquimedes, de um Descartes, de um Bichat, ou de um Augusto Comte. Demais, muitas descobertas essenciais, como a construção da teoria cerebral, ficavam também dependendo da fundação da sociologia, e esta não podia realizarse senão depois de um suficiente desenvolvimento da evolução humana, isto é, nos tempos modernos.

Por outro lado, as exigências do sentimento e da atividade não podiam ficar esperando o completo desenvolvimento científico para tomarem surto. Daí os modos provisórios para a sua solução que foram permitindo seu suficiente aperfeiçoamento, e que constituíram as diferentes civilizações que precederam à época moderna.

Assim se explica o caráter das civilizações grega (politeísmo intelectual), romana (politeísmo social), e católico-feudal, onde tomaram surto preponderante, respectivamente, a inteligência, a atividade, e o sentimento.

Mas uma vez esgotada a eficácia moral e social da fé monoteica (último modo do teologismo), e da atividade militar defensiva (último modo da vida guerreira), a verdadeira natureza do problema moderno apresentou-se como consistindo no surto definitivo do espírito relativo e da atividade pacífica, o que só se podia realizar mediante a construção das ciências superiores (a sociologia e a moral) e da organização da grande indústria.

Os poderosos obstáculos, porém, que o regime católico-feudal naturalmente tinha de opor à construção da fé científica, que logo entrou em conflito com a fé teológica, fizeram com que o movimento moderno formasse uma dupla corrente: uma, de construção dos elementos da ordem nova, e portanto positiva ou científica; outra, de decomposição dos elementos da ordem antiga, e portanto negativa e metafísica. Mas como o movimento de reconstrução tornava-se então ainda mais difícil do que nos outros períodos anteriores de interregno religioso, sucedeu que a época moderna, depois do enfraquecimento da última fé teológica, tomou um caráter extremamente revolucionário. A dificuldade principal consistia em transportar o espírito relativo aos fenômenos superiores da ordem humana (os fenômenos morais), porque, além de constituírem eles o principal domínio do teologismo, necessitavam de uma solução sintética que estava em desacordo com os hábitos de análise adquiridos durante a construção científica das ciências inferiores. Por outro lado, a indústria, que por sua natureza é individual, tinha de se tornar coletiva.

No fundo, tratava-se de regular as forças que a Humanidade havia desenvolvido na sua longa evolução, que não podia deixar de ter sido mais ou menos anárquica, desde a época teocrática. 
Para esse resultado iam convergir, desde então, os órgãos supremos da Humanidade, que se resumiram em Augusto Comte.

\section{f $F$}

Com estes preliminares pode-se bem constatar que o espírito de detalhe não é mais próprio do nosso século, e que a sua persistência, depois das ciências desenvolvidas no que havia do essencial, só que pode conduzir a pesquisas indefinidas, que se tornam, na sua grande maioria, inúteis ou ociosas. Basta considerar que, se em cada ciência a Humanidade precisasse descer aos mínimos detalhes, ainda não teria saído da matemática e da astronomia o que é bem suficiente para demonstrar de quanto o espírito analítico levado ao excesso pode prejudicar o progresso humano.

Pode-se também ainda compreender, no que respeita à arte médica, qual foi a influência e o valor da escola hipocrática. Essa influência resultou justamente de sua origem teocrática.

Herdeiro das tendências sintéticas do sacerdócio teocrático, preservado das aberrações teóricas pelo seu caráter sempre prático, o gênio de Hipócrates pôde transmitir sem alteração, aos seus sucessores, a noção fundamental do consenso orgânico. O reconhecimento de nossa indizível natureza que essa escola assim proclamava, preservou, por muito tempo, os médicos práticos das aberrações especialistas de que estavam sempre ameaçados, enquanto durou a formação analítica das teorias vitais. ${ }^{21}$

Foi só depois de fundada a química com Lavoisier e Berthollet, e constituída a biologia, pela elaboração decisiva de Bichat ${ }^{22}$, que a arte médica pode tomar novo enlace com Broussais, o verdadeiro fundador da patologia positiva. ${ }^{23} \mathrm{~A}$ fundação deste imortal gênio consistiu, por um lado, em ligar as perturbações dos fenômenos vitais à lesão dos órgãos e tecidos ${ }^{24}$, e por outro lado, em estabelecer a identidade entre a patologia e a fisiologia, a moléstia e a saúde, que só então foram consideradas como submetidas às mesmas leis, não diferindo entre si senão na intensidade dos fenômenos, cuja natureza fica sempre a mesma. ${ }^{25}$

No entanto, Broussais, segundo observa Augusto Comte, apesar de haver abordado no fim de sua carreira, o estudo do cérebro, segundo a concepção de Gall, ficou na sua construção patológica, sempre muito limitado às vidas vegetativas e animal.

Também o conhecimento positivo do cérebro só podia mesmo ser realizado depois da construção da sociologia, porque as leis mentais não podiam ser apanhadas senão no conjunto da evolução humana. E foi por esse motivo que não podia deixar de ser incompleta a admirável tentativa devida ao gênio de Gall que, primeiro, combinou a pluraridade necessária das funções cerebrais com a sua comum residência no aparelho cerebral ${ }^{26} \mathrm{e}$ cuja principal descoberta consistiu em ligar à constituição do cérebro a existência dos instintos simpáticos ${ }^{27}$, isto é, os sentimentos altruístas.

\footnotetext{
${ }^{21}$ V. Dr. Audiffrent, Appel aux médecins, págs. 136 a 138.

${ }^{22}$ V. Pol. Positiva, T.III, pág. 661.

${ }^{23}$ V. Pol. Positiva, T. IV. Examen du traité de Broussais sur l'irritation (Appendice general).

${ }^{24}$ Ibidem.

${ }^{25}$ Ibidem, T.III, pág. 616.

${ }^{26}$ Ibidem, pág. 617.

${ }^{27}$ Ibidem.
} 
Foi esta preparação cientifica, a que se devem juntar os trabalhos de Cabannis sobre as relações entre o físico e o moral, e os de Lamarck cobre a série animal, e a influência do meio, até ele desconhecida, e mais o impulso filosófico devido a Condorcet e De Maistre, que permitiram a Augusto Comte abordar o estudo positivo da sociologia, descobrindo em 1822 as duas leis sociológicas que explicam a evolução dos pensamentos humanos, e que constituem diretamente o princípio fundamental do positivismo. ${ }^{28}$

Foi construindo, com esta base, a filosofia positiva que Augusto Comte pôde depois retomar a destinação social de seus trabalhos, fundando a religião da Humanidade, depois de haver reconhecido a preponderância fundamental do coração sobre a inteligência. Mas este resultado final só foi conseguido depois do impulso afetivo que emanou da influência, primeira objetiva e depois subjetiva, de sua angélica inspiradora, Clotilde de Vaux. ${ }^{29}$

\section{f $F$}

Essas duas leis têm uma tão capital importância para se compreender a evolução especulativa, seja da Humanidade, seja de cada indivíduo, que seria imperdoável deixar de enunciá-las aqui.

Uma, de filiação histórica, indica a marcha geral do espírito humano; a outra, de classificação, indica a ordem segundo a qual se completa aquela evolução para cada categoria de fenômenos. Ficando, assim, um complemento da outra, podem ser formuladas num mesmo enunciado: "Todas as concepções humanas passam por três estados, teológico, metafísico e positivo; mas com uma velocidade proporcionada à generalidade dos fenômenos correspondentes".

Esta lei dinâmica da inteligência é a que explica também o desenvolvimento geral da Humanidade através de todas as civilizações, porque os progressos morais e materiais realizados pela evolução humana ficaram sempre subordinados ao desenvolvimento da inteligência, o que era uma fatalidade devida à nossa organização cerebral.

A Humanidade não passou de um estado para outro sem uma série de gradações. Na fase teológica deve-se destacar o fetichismo da teologia propriamente dita, que no fundo diferem mais entre si do que a teologia difere da metafísica. Eis porque, na fórmula definitiva, Augusto Comte distinguiu o fetichismo inicial, da teologia intermediária, com a metafísica, e por fim, o positivismo.

O fetichismo se caracteriza pela tendência a animar todos os corpos com atributos humanos. A teologia, ao contrario, desconhece neles qualquer espécie de atividade, atribuindo todos os fenômenos à vontade de entes sobrenaturais.

A metafísica retira destes entes os atributos humanos, a vontade, mas conserva os atributos físicos a que domina forças. Estas entidades sendo concebidas fora dos corpos, da física (natureza), foram chamadas metafísicas (além da natureza). Assim, pois, quando algum cientista imagina o calor, a eletricidade, a gravidade, a afinidade dos corpos, a energia vital como tendo existência fora dos corpos, como variações na vibratibilidade do éter, etc., faz raciocínio metafísico. No entanto, todos esses fenômenos, assim como as criações denominadas éter, átomo, força, inércia, ou são meras abstrações, ou simples hipóteses, a que os metafísicos ainda atribuem uma existência real ou os consideram como entidades independentes dos corpos.

\footnotetext{
${ }^{28}$ V. Pol. Positiva, T.IV, págs. 614 a 618.

${ }^{29}$ V. Pol. Positiva, T.IV, págs. 614 a 618.
} 
A verdadeira ciência consiste em observar os fenômenos e descobrir as suas leis, e sabe que o fenômeno só é concebido fora de sua sede, por uma faculdade da inteligência a que chamamos abstração. Para o verdadeiro cientista, não há calor, eletricidade, fora do corpo quente ou elétrico, nem vida fora do organismo vivo, nem inteligência, sentimento e caráter fora do cérebro. O que chamamos calor, eletricidade, vida, etc., não representam mais do que a constatação abstrata dos fenômenos através dos quais percebemos a existência dos seres ou corpos.

Estas verdades só podem, porém, ser reconhecidas e aceitas quando abandonamos de uma vez a maneira de raciocinar absoluta. Tudo é relativo, eis o único princípio absoluto.

Augusto Comte mostra mesmo que, em última análise, a evolução mental consistiu em fazer o espírito passar do estado absoluto ao estado relativo, sendo que este último só pode ser conseguido pela completa maturidade da inteligência, quando o espírito positivo, estendido a todos os fenômenos, nos leva a reconhecer a impossibilidade em que nos achamos de conhecer a natureza íntima deles, ou de penetrar suas causas primárias e finais, cuja pesquisa constituiu sempre o objeto da teologia e da metafísica.

A segunda lei explica como uma mesma pessoa pode raciocinar cientificamente, isto é, positivamente a respeito de certos fenômenos, enquanto que para outros o seu raciocínio fica teológico ou metafísico. É que o raciocínio positivo é mais ou menos fácil, segundo a simplicidade maior ou menor dos fenômenos, o que depende, por sua vez, da sua maior ou menor generalidade. Assim, ninguém se lembra de invocar a deus para compreender que a soma dos 3 ângulos de um triângulo valem 2 retos. Mas nem todos estão nos casos de aceitar que podemos amar ou pensar sem a graça divina, ou sem alguma força psíquica especial. A simplicidade dos fenômenos, no primeiro caso, e a complicação deles no segundo, explica a maior ou menor dificuldade do raciocínio positivo.

A instituição de série enciclopédica, ou classificação natural das ciências, resulta desta lei..$^{30}$

Com estes preliminares podemos agora dar algumas indicações a respeito da teoria cerebral construída por Augusto Comte, o quanto nos parecer necessário à concepção positiva da teoria da unidade, da moléstia, e dos sintomas chamados epilépticos que constituem propriamente aqui o nosso objeto. Insistiremos apenas, um pouco mais, nos pontos que se acham mais controvertidos pelas teorias atuais, metafísicas e materialistas. ${ }^{31}$

(Continua)

\footnotetext{
${ }^{30}$ Só existem sete ciências, correspondentes às sete categorias de fenômenos conhecidos. Classificadas segundo a generalidade decrescente a complicação crescente dos fenômenos correspondentes, são: a matemática, a astronomia, a física, a química, a biologia, a sociologia e a moral. Todos os outros grupos de conhecimentos que se decoram com o nome de ciência, como a geologia, meteorologia, mineralogia, etc., não são mais do que repositórios de dados concretos sem suficiente ligação, e onde se torna impossível qualquer previsão, que é só o que dá o caráter cientifico a qualquer categoria de conhecimentos. Esta, a previsão, só é possível mediante o conhecimento das leis abstratas. Eis porque e não é possível instituir uma ciência concreta.

- Sobre a instituição da série enciclopédica, v. Augusto Comte, Pol. Positive, T.III, Première partie, Esprit fondamental du positivisme; Ibidem, T.III. págs. 21 a 53; Catecismo positivista, págs. 180 a 226; Teixeira Mendes, As últimas concepções de Augusto Comte, págs. 281 a 291.

${ }^{31}$ V. Augusto Comte, Système Politique Positive, T.I, pág. 669 a 735; Dr. Audiffrent, Du cerveau et de l'innervation; Ibidem, Maldies du cerveau et de l'innervation; Ibidem, Appel aux médecins; Teixeira Mendes, Harmonia mental (Sumárias indicações acerca da teoria positiva dos estados cerebrais denominados: razão, loucura, alienação e idiotismo), publ. n. 30 do Apost. Posit. do Brasil; Dr. Robinet, - Introduction aux Lettres sur les animaux, de J. Leroy, Edition 1896.
} 